
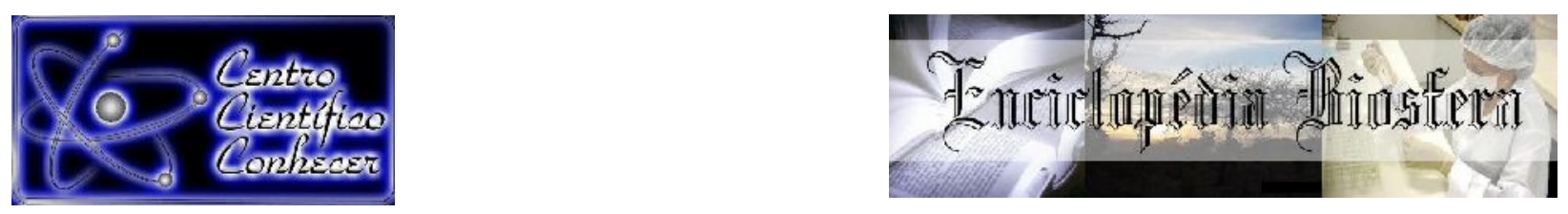

\title{
DIMENSIONAMENTO DE UMA UNIDADE INDUSTRIAL PARA A EXTRAÇÃO DA PECTINA A PARTIR DA CASCA DO MARACUJÁ AMARELO
}

\author{
Nattália Tose Lopes ${ }^{1}$, Thaísa Frossard Coslop ${ }^{1}$, Ramiro Picoli Nippes ${ }^{1}$, \\ Vanessa Dal-Bó ${ }^{1}$, Flávia Pereira Puget ${ }^{2}$ \\ ${ }^{1}$ Bacharel em Engenharia Química pelas Faculdades Integradas de Aracruz \\ (FAACZ), Aracruz, ES, Brasil. \\ E-mail: vanessadalbo1@gmail.com \\ ${ }^{2}$ Professora Doutora do curso de Química Industrial do Instituto Federal do Espirito \\ Santo - Ifes Campus Aracruz
}

Recebido em: 15/02/2020 - Aprovado em: 15/03/2020 - Publicado em: 30/03/2020

DOI: 10.18677/EnciBio_2020A6

\begin{abstract}
RESUMO
Atualmente, parte da produção nacional de maracujá amarelo é destinada ao processamento para obtenção de suco, gerando uma elevada quantidade de resíduos, sendo as cascas o mais volumoso. Uma alternativa para o reaproveitamento dessas cascas é a sua utilização como matéria-prima para a extração de pectina, um polissacarídeo com função gelificante aplicada na indústria alimentícia, farmacêutica e cosmética. Com isso tornou-se relevante, realizar uma proposta de dimensionamento e seleção de equipamentos de uma unidade industrial para obtenção da pectina, com alto grau de esterificação, a partir da casca do maracujá amarelo (Passiflora Edulis Flavicarpa). Foram definidas as etapas do processo industrial tendo como base, a extração da pectina em laboratório realizada por Arrigoni et al., (2013) e por meio dos dados fornecidos pela Cooperativa de Produtores Rurais de Jaguaré - COOPRUJ. Por meio do dimensionamento do processo produtivo foi possível estimar uma produção de 53 toneladas de pectina ao ano. Com a adição de uma coluna de destilação, foi possível recuperar cerca de 90 $\%$ do etanol gasto para a precipitação alcoólica da pectina.
\end{abstract}

PALAVRAS-CHAVE: Modelagem. Grau de Esterificação. Resíduo.

\section{SIZING OF AN INDUSTRIAL UNIT FOR THE EXTRACTION OF PECTIN FROM THE PEEL OF THE YELLOW PASSION FRUIT}

\begin{abstract}
Currently, part of the national production of yellow passion fruit is destined for processing to obtain juice, which generates a high amount of waste, being peels the bulkiest part. As an alternative for the reuse of these peels is its use as a raw material for the extraction of pectin, a polysaccharide with gelling function applied in the food, pharmaceutical and cosmetic industry. Therefore, it becomes relevant to design and select equipment for an industrial unit to obtain pectin, with a high degree of esterification, from the yellow passion fruit peel (Passiflora Edulis Flavicarpa). The
\end{abstract}


stages of the industrial process were defined based on the extraction of pectin in the laboratory performed by Arrigoni et al., (2013) and through data provided by the Cooperative of Rural Producers of Jaguaré - COOPRUJ. By sizing the production process, it was possible to estimate a 53 tons per year production of pectin. The addition of a distillation column makes possible to recover about $90 \%$ of the ethanol used for the alcoholic precipitation of the pectin.

KEYWORDS: Modeling. Degree of Esterification. Residue.

\section{INTRODUÇÃO}

Oriundo da América tropical, o maracujá (Passiflora Edulis) é amplamente cultivado e processado em todo o mundo. O Brasil destaca-se como principal produtor, com cerca de $90 \%$ da produção mundial. Dados do IBGE (2018), indicam que foram colhidas aproximadamente 600 mil toneladas de maracujá em 43,25 hectares, no decorrer da safra de 2018. Parte da produção comercializada é destinada ao consumo in natura e o restante é destinado às indústrias de processamento, sendo o suco o principal produto derivado (SILVA et al., 2017). O processamento do maracujá gera um elevado volume de resíduo, que é constituído basicamente por cascas e sementes, os quais correspondem cerca de $70 \%$ do peso do fruto (OLIVEIRA et al., 2016).

O resíduo de frutas apresenta um elevado teor de açúcares, o que os torna muito suscetíveis ao desencadeamento de processos fermentativos. Além disso, acarreta a proliferação de insetos, exala mau cheiro nos locais de descarga e passam a servir de foco para a presença de animais (FERREIRA; PENA, 2010). As pectinas são polissacarídeos estruturais, encontradas na parede celular primária e nas camadas intercelulares de plantas. Estas estão associadas à celulose, hemicelulose e lignina e são mais abundantes em frutos, destacando-se as cascas dos frutos cítricos (LARA-ESPINOZA et al., 2018).

A extração da pectina pode ser realizada a partir de métodos térmicos, químicos ou enzimáticos, destacando-se o método químico em meio ácido, que resulta em maiores rendimentos (ZAID et al., 2016; MANEERAT et al., 2017). A pectina geralmente é classificada quanto ao grau de esterificação (GE), em pectinas de baixo (<50\%) e alto (> 50\%) GE (ADETUNJI et al., 2017). Pectinas de alto grau de esterificação são consideradas mais importantes e são amplamente usadas como agentes gelificantes na produção de geleias, marmeladas, estabilizantes de bebidas e sorvetes e produtos de confeitaria. Além disso, novos usos estão sendo constantemente desenvolvidos na indústria de alimentos e também em aplicações farmacêuticas e cosméticas.

Devido à vasta aplicabilidade da pectina, a quantidade de resíduos gerados no beneficiamento do fruto e à escassez de empresas produtoras de pectina no Brasil, torna-se relevante à realização de uma proposta de dimensionamento e seleção de equipamentos de uma unidade industrial para obtenção da pectina, com alto grau de esterificação, a partir da casca do maracujá amarelo.

De acordo com Schultz et al. (2014), é importante representar os processos por meio de equações matemáticas, assim é possível testar diversas possibilidades de configuração dos equipamentos e das etapas, além de buscar a idealidade e prever o comportamento em situações adversas.

Esse estudo teve como base a otimização experimental da extração realizada por Arrigoni et al. (2013), desenvolvida nos laboratórios das Faculdades Integradas de Aracruz (FAACZ), o que proporciona confiabilidade nos dados utilizados para a 
realização do trabalho. O objetivo deste trabalho foi apresentar uma proposta de dimensionamento e seleção de equipamentos de uma unidade industrial para a obtenção da pectina, com alto grau de esterificação, extraída a partir da casca do maracujá amarelo (Passiflora Edulis Flavicarpa), buscando um processo mais eficiente e econômico.

\section{MATERIAL E METODOS}

Para a implantação de qualquer nova empresa é necessário que o empreendedor determine as etapas fundamentais para atingir os objetivos e consequentemente o sucesso empresarial. Com isso foi analisado o processo de obtenção da pectina a partir da casca do maracujá amarelo, e elaborado o plano de produção que engloba o processo produtivo, o dimensionamento, a seleção e as especificações dos equipamentos.

\section{Processo Produtivo}

Para a elaboração das etapas do processo produtivo, foi utilizada como base a sequência de experimentos para a extração da pectina em laboratório por Arrigoni et al. (2013). Os experimentos seguiram as etapas apresentadas no fluxograma da Figura 1.

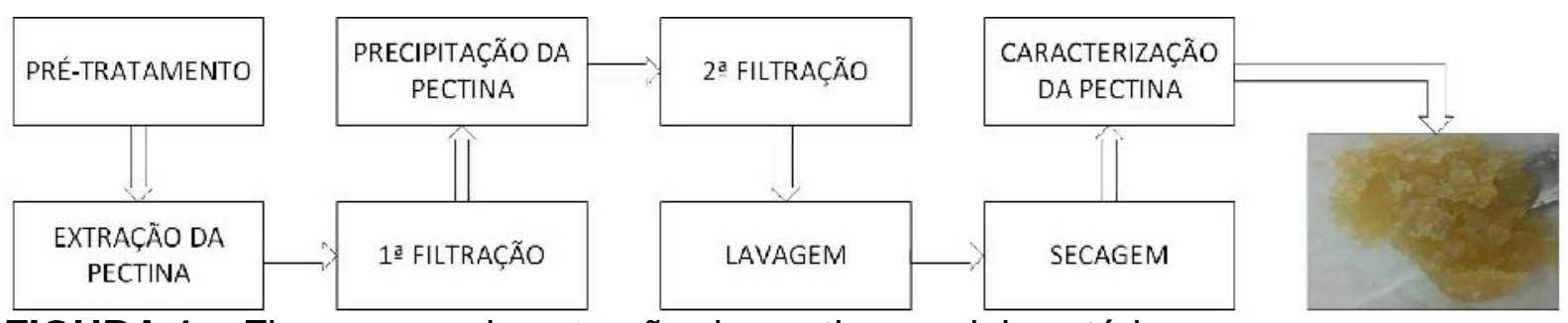

FIGURA 1 - Fluxograma da extração da pectina em laboratório.

Fonte: Adaptado de Arrigoni et al. (2013).

O fluxograma descreve todas as etapas da obtenção da pectina em laboratório, sendo que a extração e a lavagem são as etapas mais relevantes na otimização dos ensaios, ambas exigem cuidados no momento de operação. Na extração são controladas as variáveis interferentes do processo ( $\mathrm{pH}$, temperatura e tempo), e na lavagem pode ocorrer a solubilização da pectina, além de não eliminar todos os resíduos decorrentes da extração.

As condições operacionais utilizadas nesta proposta de dimensionamento da planta de extração da pectina, foram determinadas por Arrigoni et al. (2013) por meio do delineamento composto central rotacional (DCCR), um modelo matemático, que prevê a otimização dos fatores interferentes. Os valores otimizados de $\mathrm{pH}$, tempo e temperatura que levam ao melhor grau de esterificação e rendimento são mostrados na Tabela 1.

TABELA 1 - Condição Operacional otimizada

\begin{tabular}{ccccccc}
\hline \multicolumn{3}{c}{ Variáveis independentes } & & \multicolumn{2}{c}{ Variáveis dependentes } \\
\cline { 1 - 2 } pH & Tempo (min) & Temperatura $\left({ }^{\circ} \mathbf{C}\right)$ & & Rendimento (\%) & GE (\%) \\
\hline 3,8 & 24,1 & 96 & & 15 & 72,3 \\
\hline
\end{tabular}

Fonte: Adaptado de Arrigoni et al. (2013). 


\section{Dimensionamento do Processo Produtivo}

A modelagem dos equipamentos do processo foi obtida com base nas leis básicas de conservação de massa e energia, em estado estacionário, sem reação química, com o objetivo de determinar as principais correntes do processo. Primeiramente foram definidas as variáveis que influenciam cada etapa do processo, como, por exemplo, volume inicial e vazões de entrada e saída.

\section{Seleção e especificações dos equipamentos}

A seleção e especificação dos equipamentos foi feita a partir do processo produtivo, definido neste trabalho, e do dimensionamento do mesmo. Por meio dos cálculos de modelagem, foi possível estimar a capacidade de produção da planta química e determinar o tipo de equipamento que melhor se adequa a cada etapa.

\section{Processo produtivo}

\section{RESULTADOS E DISCUSSÕES}

O processo de obtenção da pectina, realizado em bateladas, consistiu na preparação da matéria-prima, extração, precipitação e tratamento final da pectina, além da sua caracterização.

\section{Preparação da matéria-prima}

A preparação da matéria-prima (Figura 2) baseou-se em uma sequência de operações pelas quais irão passar as cascas do maracujá amarelo, com a finalidade de facilitar a extração da pectina.

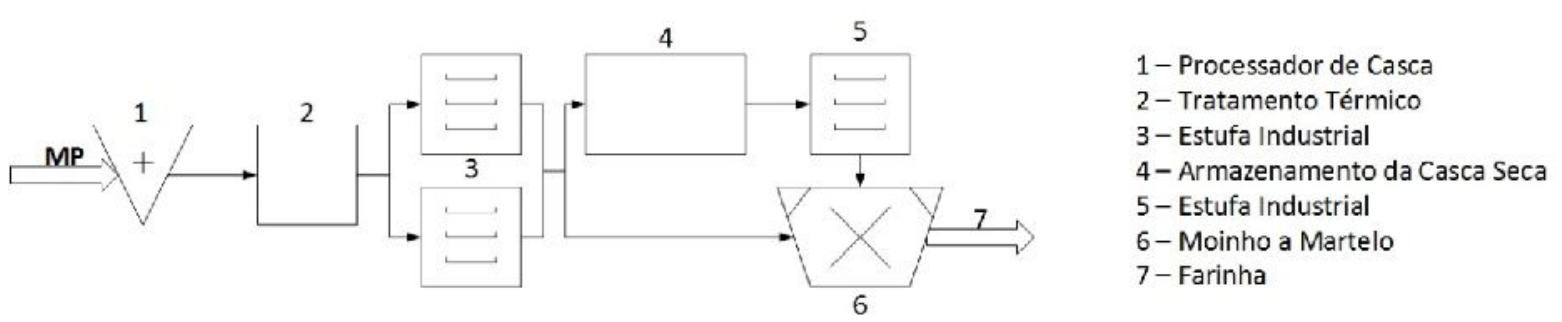

FIGURA 2 - Fluxograma da preparação da matéria-prima.

O transporte da casca deve ser feito através de caminhões frigoríficos, visto que a casca se deteriora facilmente em condições ambientes. A matéria-prima recebida passa por um processador de casca (1) com intuito de picar e consequentemente aumentar a superfície de contato das cascas o que facilita sua posterior secagem. Em seguida passa por um tratamento térmico (2), por imersão em água em ebulição durante cinco minutos, para inativações enzimáticas.

A secagem é realizada em estufas industriais (3) a uma temperatura de $50{ }^{\circ} \mathrm{C}$, de modo a se obter uma umidade máxima de $15 \%$, o que permite armazenar a casca seca sem perigo de deterioração, além de diminuir o volume de armazenamento.

A casca é estocada em sala climatizada (4) a uma temperatura máxima de $16^{\circ} \mathrm{C}$. Posteriormente passa por uma estufa (5) para atingir temperatura ambiente, $\mathrm{e}$ segue para a moagem em moinho a martelo (6) para alcançar uma granulometria máxima de $2 \mathrm{~mm}$. Depois de moída, a farinha (7) segue para o processo de extração. 


\section{Extração da Pectina}

Nessa operação são adicionados, simultaneamente ao extrator, a farinha (7) e a solução tampão (8) de oxalato de amônio/ácido oxálico $(\mathrm{pH}=3,8)$, que permanecem sob refluxo a uma temperatura de $96{ }^{\circ} \mathrm{C}$, por um tempo de 24,1 minutos. Para essa operação é utilizado um tanque de aquecimento acoplado a um condensador (9). O reúso da água, proveniente da etapa de condensação é necessário, porém a forma de aplicação prática depende de um estudo econômicofinanceiro. Uma alternativa, caso o reúso não seja possível, é o despejo em um corpo hídrico, desde que a temperatura máxima de $40^{\circ} \mathrm{C}$, conforme estabelecido pela resolução CONAMA, 20/86, seja atendida e, o local de instalação da unidade de produção da pectina permita. A Figura 3 ilustra o processo de extração detalhado.

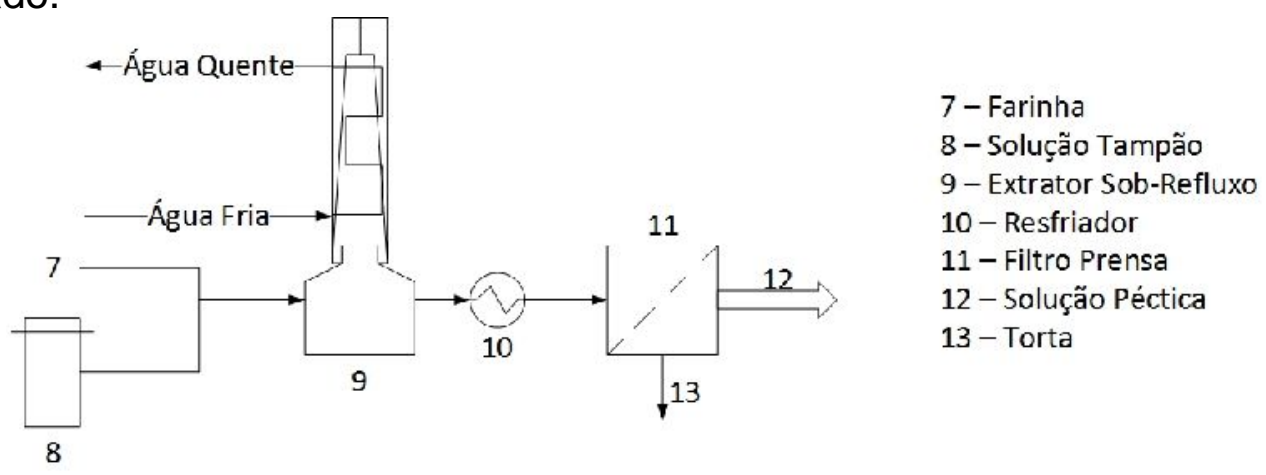

FIGURA 3 - Fluxograma do processo de extração da pectina.

Após a extração a mistura contendo pectina passa por um resfriador (10) e depois por um filtro prensa (11) para eliminar a torta (13), a qual poderá vir a ser comercializada para empresas que fabricam rações para animais, ou até mesmo para compostagem, uma vez que este resíduo não apresenta contaminações.

\section{Precipitação da pectina}

Nessa etapa a solução (12) segue para um tanque de descanso (15) onde é adicionado etanol (14) na proporção 1:1 e após leve agitação permanece em repouso por 30 minutos para a precipitação da pectina, já que a pectina é insolúvel em etanol. O processo é demonstrado na Figura 4.

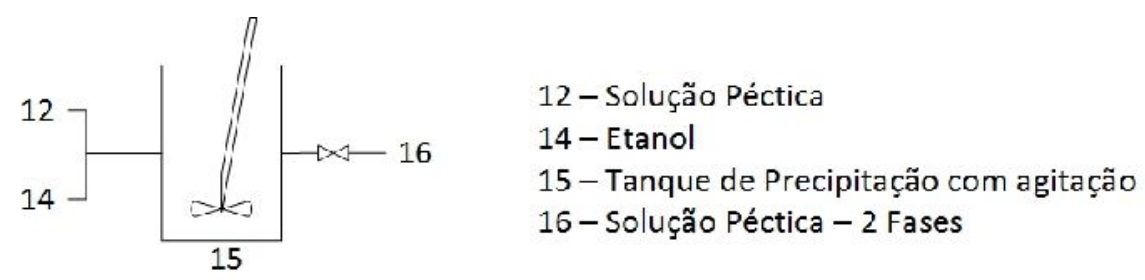

FIGURA 4 - Fluxograma do processo de precipitação da pectina.

\section{Tratamento final da pectina}

Após o tempo de repouso, a solução péctica (16), separada em duas fases, segue para o filtro rotativo (17), onde ocorrem lavagens, com etanol (22), para separação da pectina da solução etanólica. A pectina segue para uma estufa (18), a temperatura de $50^{\circ} \mathrm{C}$, e depois é moída em um moinho de facas (19). A partir daí, são coletadas amostras de pectina para a caracterização, a qual é feita no 
laboratório da própria empresa por meio de titulação de titrimetria de neutralização, que permite obter o grau de esterificação, o qual deve ser superior a $50 \%$. Depois de caracterizada a pectina segue direto para 0 setor de embalagem $e$ armazenagem.

O líquido etanólico que sai do moinho passa por um processo de destilação (20) para a recuperação do etanol. O etanol retorna ao processo na etapa de precipitação (15) e também no filtro rotativo (17) para as lavagens. As etapas do tratamento final são demonstradas no fluxograma da Figura 5.

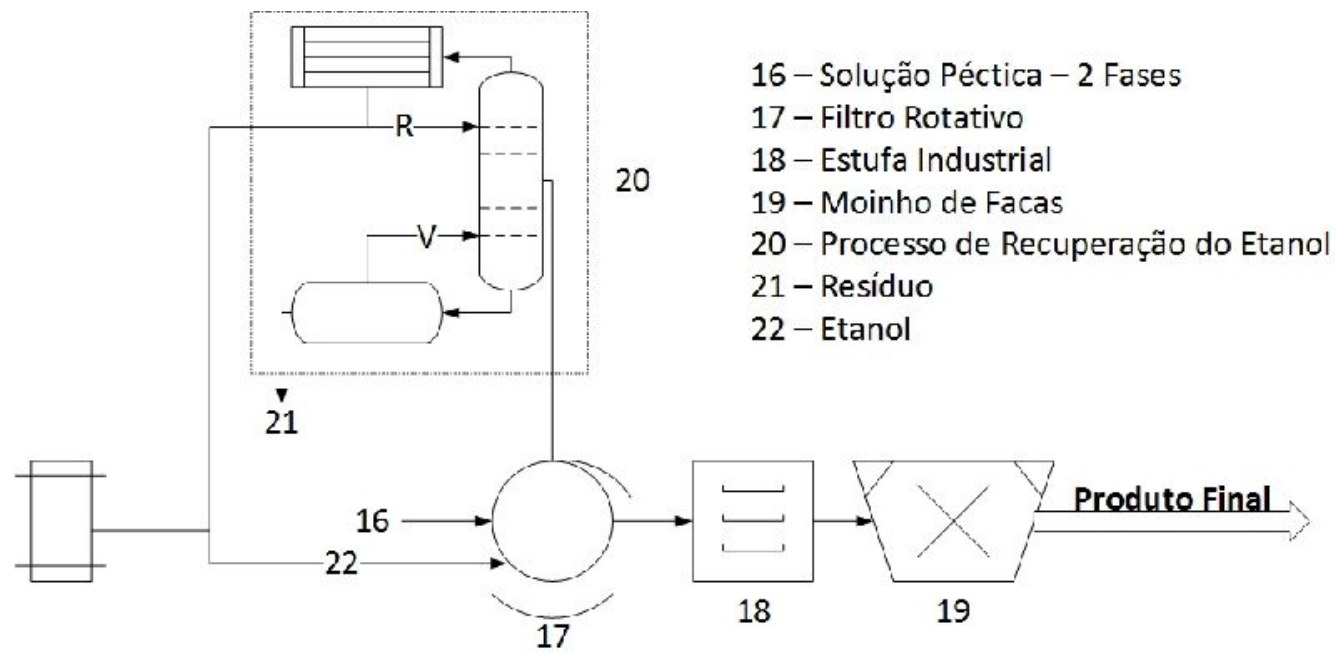

FIGURA 5 - Fluxograma do processo de recuperação do etanol e tratamentos finais da pectina.

\section{Dimensionamento do processo produtivo}

Determinadas as etapas para a obtenção industrial da pectina, foi possível identificar as principais correntes de entrada e saída do processo. Com a finalidade de simplificar os cálculos, o fluxograma usado como base para a realização da modelagem é demonstrado na Figura 6.

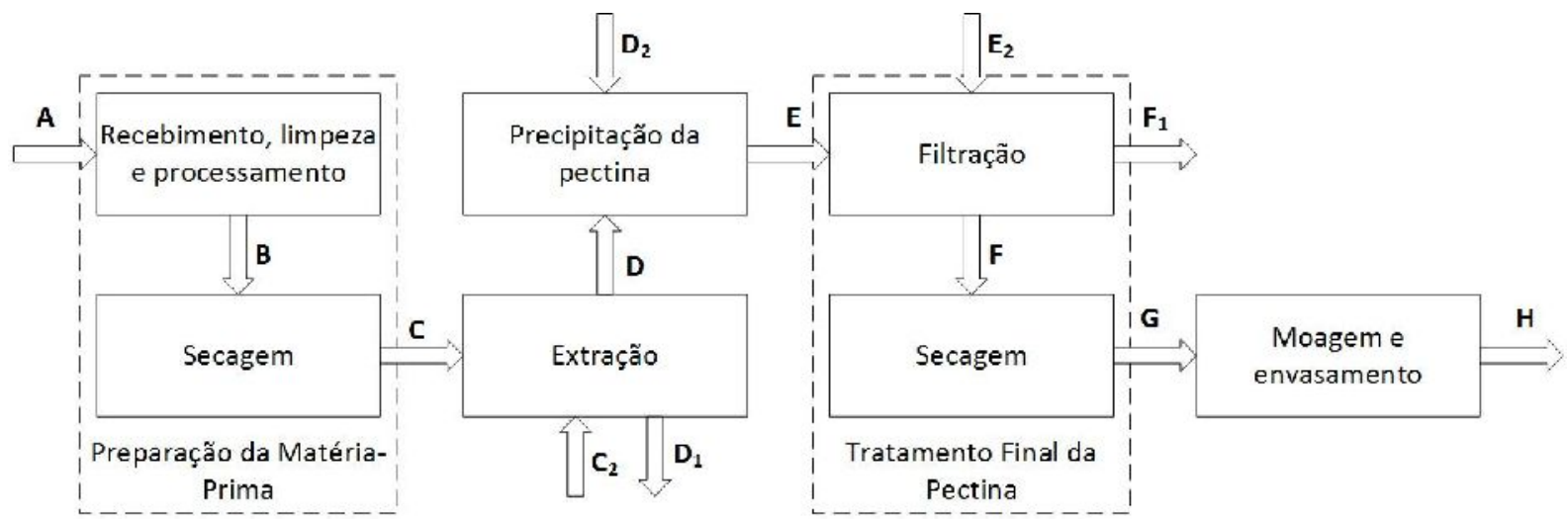

FIGURA 6 - Fluxograma do processo de obtenção da pectina.

Preparação da matéria-prima

A preparação da matéria-prima engloba duas etapas, a primeira inclui o recebimento, limpeza e processamento da casca, e a segunda consiste na secagem. 
A definição da vazão de entrada do processo $\left(m_{A}\right)$ foi baseada na quantidade de maracujá vendida pela COOPRUJ, no ano de 2012, para as empresas de processamento de polpa de frutas no estado do Espirito Santo. O volume de controle para a primeira etapa do processo encontra-se na Figura 7.

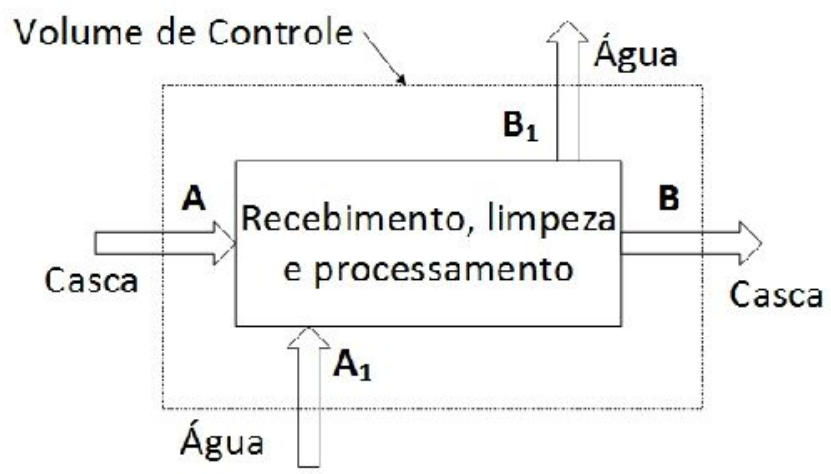

FIGURA 7 - Volume de controle para a etapa 1 do preparo da matéria-prima.

Sabendo que a cooperativa vende em média 5000 t/a de maracujá, e que cerca de $60 \%$ do fruto é casca, estima-se a geração de 3000 t/a $(342,5 \mathrm{~kg} / \mathrm{h})$ de casca. Admitindo que nessa etapa do processo não ocorrem perdas, então entrada=saída, logo: $m_{A}=m_{B}$.

Os experimentos realizados por Arrigoni et al. (2013) sugerem o uso de dois litros de água para cada quilograma de casca de maracujá cortada. Logo para a etapa de inativação enzimática, são utilizados $684,9 \mathrm{~L} / \mathrm{h}$ de água. Realizando o balanço material global no sistema, encontra-se a vazão mássica da corrente de saída através da Equação 1.

$$
m_{A}+m_{A 1}=m_{B}+m_{B 1}
$$

A segunda etapa está ilustrada na Figura 8 . A casca úmida é submetida ao secador com uma umidade inicial $\left(\theta_{i}\right)$ de $90 \%$ e precisa ser seca para garantir uma umidade final $\left(\theta_{f}\right)$ de $15 \%$.

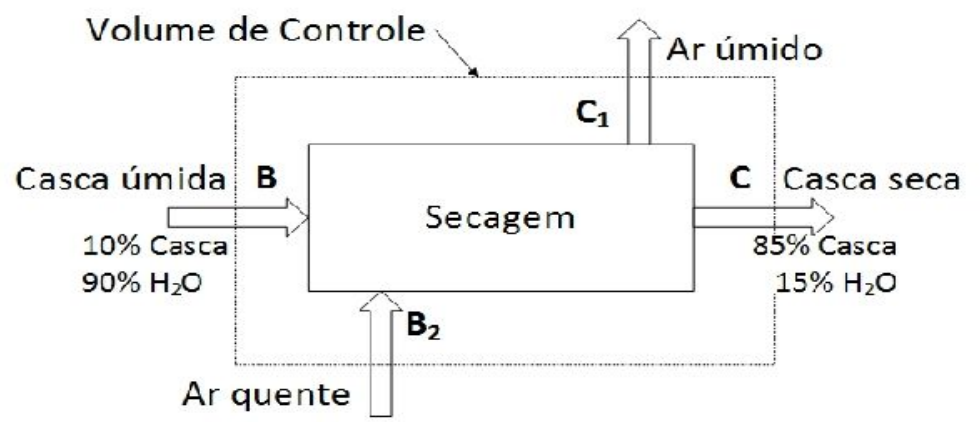

FIGURA 8 - Volume de controle para a etapa de secagem.

A corrente de entrada $B$ é constituída de $10 \%$ de casca $\left(x_{\text {casca }}^{B}\right)$ e a corrente $C$ de $85 \%\left(x_{\text {casca }}^{C}\right)$. A vazão mássica de casca seca $\left(m_{C}\right)$ é determinada aplicando o balanço material para os sólidos no sistema (Equação 2).

$$
m_{B} \quad x_{\text {casca }}^{B}=m_{C} \quad x_{\text {casca }}^{C}
$$


A vazão mássica da corrente de ar quente $\left(m_{B 2}\right)$ pode ser obtida pela Equação 3 , dada pela relação entre a vazão mássica de água evaporada $\left(m_{H 2 O}\right)$ e a diferença de umidade absoluta do ar, $\Delta x$, que consiste na diferença entre $x_{1}$, umidade absoluta do ar na entrada do secador (ar quente), e $x_{2}$, umidade absoluta do ar na saída do secador (ar úmido). Os valores de $x_{1}$ e $x_{2}$ são encontrados através do diagrama psicométrico.

$$
m_{B 2}=m_{H 2 O} / \Delta x
$$

A vazão mássica de água evaporada é obtida conforme Equação 4.

$$
m_{H 2 O}=m_{B} \quad \theta_{1}-m_{C} \quad \theta_{f}
$$

Para esse caso, é possível determinar $x_{2}$ estimando o valor de $25^{\circ} \mathrm{C}$ para a temperatura do ar ambiente ( $T^{a r}$ ambiente) e o valor de $60 \%$ para a umidade relativa do ar $\left(\Phi_{1}\right)$. A partir desses dois valores, encontra-se 0 valor de $x_{2}$ no diagrama psicométrico, $x_{2}=13 \mathrm{~g} \mathrm{H}_{2} \mathrm{O} / \mathrm{kg}$ ar.

Para determinar $x_{1}$, é necessário estimar a temperatura do ar de secagem ( $T^{\text {ar }}$ secagem) e a umidade relativa do $\operatorname{ar}\left(\Phi_{2}\right)$, na saída do secador. Considera-se então, $\Phi_{2}$ igual a $50 \%$ e $T^{a r}$ secagem igual a $50{ }^{\circ} \mathrm{C}$ (ARRIGONI et al., 2013). A fim de evitar uma recondensação, torna-se necessário manter a diferença de $10 \%$ entre as umidades relativas do ar (COSTA, 2007). De posse desses dois valores, e mais o valor de $x_{2}$, encontra-se o valor da umidade absoluta do ar na saída do secador: $x_{1}=44 \mathrm{~g} \mathrm{H}_{2} \mathrm{O} / \mathrm{kg}$ ar. Assim, $\Delta x=x_{1}-x_{2}=0,031 \mathrm{~g} \mathrm{H}_{2} \mathrm{O} / \mathrm{kg}$ ar. Do valor obtido para $m_{B 2}$, determina-se a corrente de ar úmido através do balanço material para as correntes de $\operatorname{ar}$ (Equação 5).

$$
m_{C 1}=m_{B 2}+m_{H 2 O}
$$

A Tabela 2 mostra os dados e os valores de cada corrente da etapa preparação da matéria-prima.

TABELA 2 - Balanço material para a preparação da matéria-prima.

\begin{tabular}{cc}
\hline Variável & Valor \\
\hline$m_{A}=m_{B}$ & $342,5 \mathrm{~kg} / \mathrm{h}$ \\
$m_{A 1}=m_{B 1}$ & $684,9 \mathrm{~kg} / \mathrm{h}$ \\
$m_{C}$ & $40,3 \mathrm{~kg} / \mathrm{h}$ \\
$m_{C 1}$ & $10.049,8 \mathrm{~kg} / \mathrm{h}$ \\
$m_{B 2}$ & $9.747,6 \mathrm{~kg} / \mathrm{h}$ \\
$m_{H 2 O}$ & $302,2 \mathrm{~kg} / \mathrm{h}$ \\
$\Delta x$ & $0,031 \mathrm{~kg} \mathrm{H} \mathrm{H}_{2} / \mathrm{kg} \mathrm{ar}$ \\
\hline
\end{tabular}


Extração da pectina

O volume de controle do processo de extração está demonstrado na Figura 9.

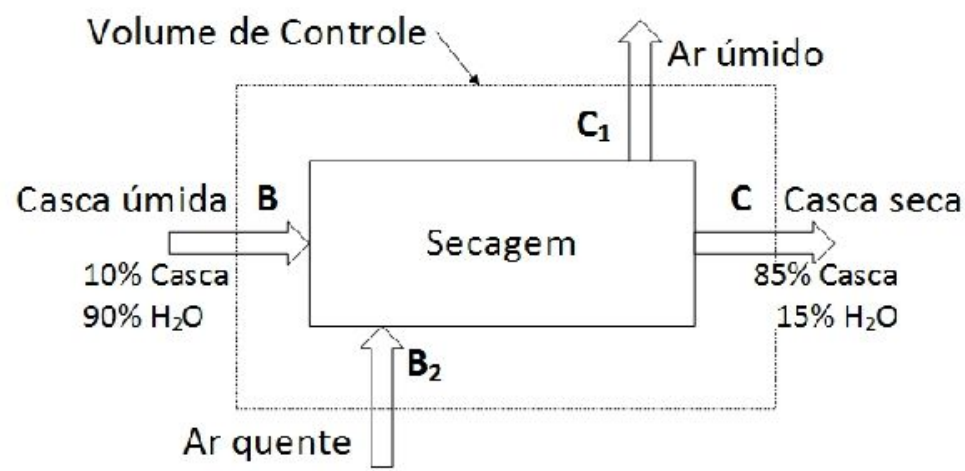

FIGURA 9 - Volume de controle para a extração

As correntes constituídas de sólidos no sistema, representadas na Figura 10, são denominadas pela corrente de entrada $C$, contendo $100 \%$ de farinha $\left(x^{C}\right.$ sólidos $)$, e pela corrente de saída $D_{1}$, formada por $99,75 \%$ de sólidos $\left(x^{D 1}\right.$ sólidos $)$. A vazão mássica da corrente da torta $\left(m_{D 1}\right)$ pode ser determinada através do balanço material para os sólidos existentes na etapa de extração (Equação 6), visto que se conhece a vazão de sólidos $\left(m_{C}\right)$.

$$
m_{C} \quad x_{\text {sólidos }}^{C}=m_{D 1} \quad x^{D 1} \text { sólidos }
$$

Os líquidos existentes no processo estão presentes na corrente de entrada de solução tampão $\left(C_{2}\right)$, constituindo $100 \%$ da corrente $\left(x^{C 2}\right.$ tampão). Já nas saídas, está presente na corrente $D$ com $100 \%$ de solução péctica ( $x_{\text {sçPéctica }}^{D}$ ), e na corrente $D_{1}$, com $0,25 \%$ de líquidos $\left(x^{D 1}\right.$ sçPéctica), já que parte da solução péctica fica retida na torta. Sabendo que $m_{C} / V_{C 2}=1 / 50(\mathrm{~m} / \mathrm{V})$, e realizando o balanço material para o líquido, determina-se a vazão volumétrica da corrente de solução péctica $\left(V_{D}\right)$ por meio da Equação 7.

$$
V_{C 2} \quad x_{\text {tampão }}^{C 2}=V_{D} \quad x_{\text {sçPéctica }}^{D}+m_{D 1} \quad x^{D 1}{ }_{\text {sçPéctica }}
$$

A vazão mássica de água $\left(\dot{m}_{W}\right)$, necessária para condensar o vapor de solução tampão, pode ser determinada utilizando a consideração de que todo o calor transmitido por unidade de tempo, pelo fluido quente, $Q_{q}$, foi recebido pelo fluido frio, $Q_{f}$, não havendo perdas, assim, igualando as duas variáveis, $Q_{f}=Q_{q}$, é possível chegar a Equação 8.

$$
Q_{f}=Q_{q}=m_{W, f} \quad c_{f} \quad\left(T_{f, s}-T_{f, e}\right)=m_{C 2, q} \quad c_{q} \quad\left(T_{q, s}-T_{q, e}\right)
$$

Onde $Q_{f}$ é o calor transmitido por unidade de tempo do fluido frio, $m_{W, f}$ a vazão mássica de água a temperatura ambiente, $c_{f}$ o calor especifico do fluido frio $(4,19 \mathrm{~kJ} / \mathrm{kg} . \mathrm{K}), T_{f, e}$ e $T_{f, s}$ a temperatura do fluido frio na entrada e na saída do condensador, respectivamente. E, $Q_{q}$ o calor transmitido por unidade de tempo do fluido quente, $m_{C 2, q}$ a vazão mássica de solução tampão a $96{ }^{\circ} \mathrm{C}, c_{q}$ a capacidade 
calorifica do fluido quente, $T_{q, e}$ e $T_{q, s}$ a temperatura do fluido quente na entrada e na saída do condensador, respectivamente.

O calor especifico do fluido quente (solução tampão) foi determinado através da técnica de calorimetria em laboratório, resultando em $1,75 \mathrm{~kJ} / \mathrm{kg} . \mathrm{K}$, e a temperatura de saída do fluido quente foi estimada com uma variação de $\pm 1^{\circ} \mathrm{C}$ em relação a temperatura de entrada do fluido quente (ARRIGONI et al., 2013).

A temperatura do fluido frio de saída foi determinada em $40{ }^{\circ} \mathrm{C}$, já que deve obedecer ao artigo 21b da resolução CONAMA $n^{\circ}$ 20, de 18 de junho de 1986, onde a temperatura dos efluentes de uma fonte poluidora não deve ultrapassar o valor de $40{ }^{\circ} \mathrm{C}$ para serem lançados em corpos d'água.

A Tabela 3 mostra os valores de cada corrente da etapa de extração.

TABELA 3 - Balanço material para a etapa de extração da pectina.

\begin{tabular}{cc}
\hline Variável & Valor \\
\hline$m_{D 1}$ & $40,4 \mathrm{~kg} / \mathrm{h}$ \\
$V_{D}$ & $2.014,4 \mathrm{~L} / \mathrm{h}$ \\
$V_{C 2}$ & $2014,5 \mathrm{~L} / \mathrm{h}$ \\
$m_{W, f}=m_{W, q}$ & $56,15 \mathrm{~kg} / \mathrm{h}$ \\
\hline
\end{tabular}

Precipitação da Pectina

A precipitação da pectina consiste na adição de etanol à solução péctica. Nessa etapa ocorre uma perda de $25 \%$ da pectina extraída, devido parte da pectina não se solubilizar totalmente. O volume de controle para essa etapa está representado na Figura 10.

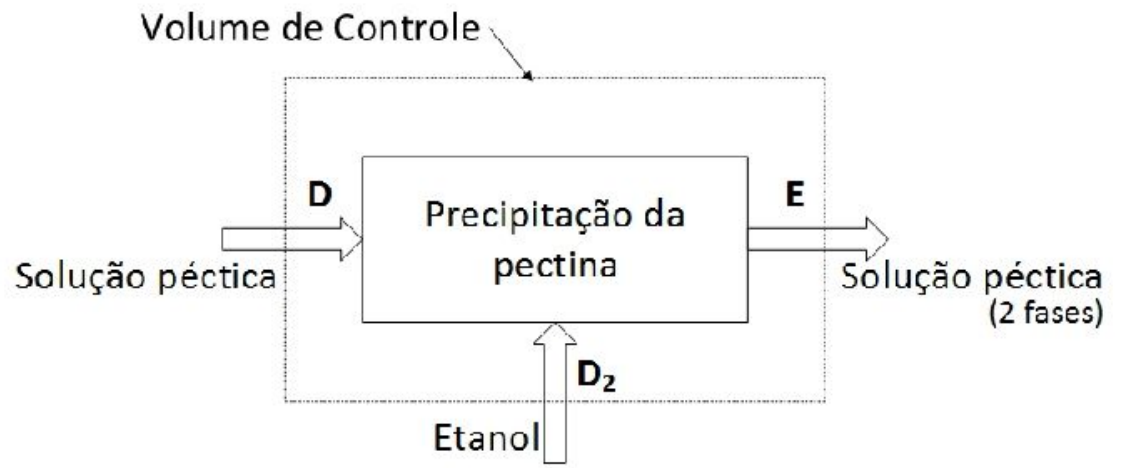

FIGURA 10 - Volume de controle para a precipitação da pectina

Conhecendo as entradas do sistema, já que conforme definido experimentalmente, $V_{D} / V_{D 2}=1$, é possível determinar a vazão volumétrica de saída $\left(V_{E}\right)$ do tanque através da Equação 9.

$$
V_{D}+V_{D 2}=V_{E}
$$

A Tabela 4 indica os valores de cada corrente dessa etapa. 
TABELA 4 - Balanço material para a precipitação da pectina.

\begin{tabular}{cc}
\hline Variável & Valor \\
\hline$V_{D 2}$ & $2014,4 \mathrm{~L} / \mathrm{h}$ \\
$V_{E}$ & $4028,8 \mathrm{~L} / \mathrm{h}$ \\
\hline
\end{tabular}

\section{Tratamento Final da Pectina}

$\mathrm{O}$ tratamento final da pectina consiste em três etapas fundamentais. A primeira composta pela filtração, a segunda pela secagem, e a terceira etapa formada pela moagem e envasamento. Contando também com uma etapa complementar aliada a filtração, a recuperação do etanol. Os volumes de controle do tratamento final da pectina estão ilustrados na Figura 11.

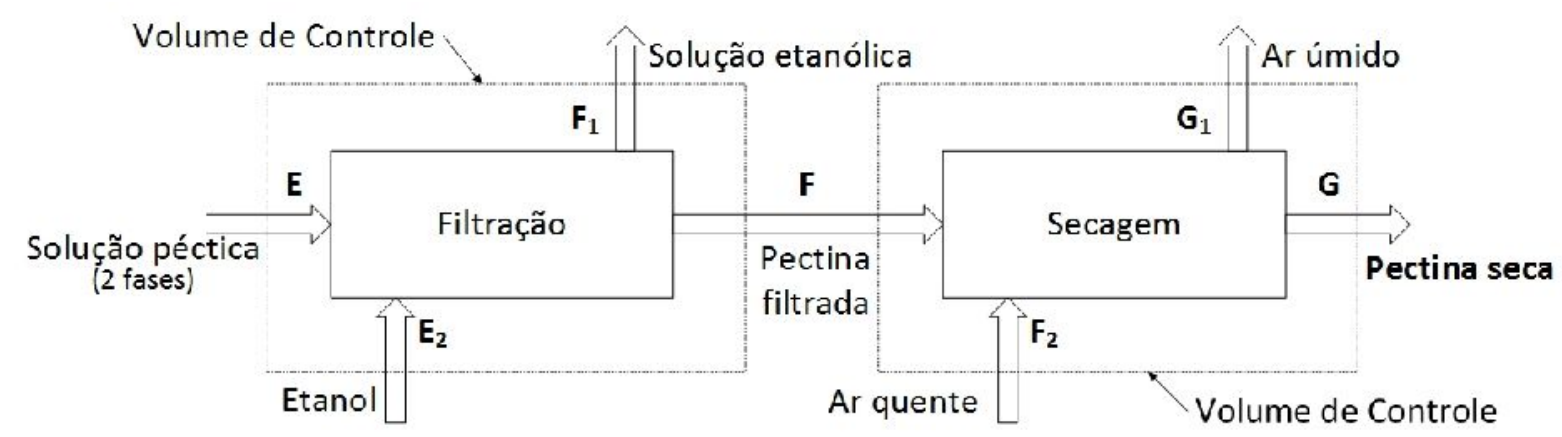

FIGURA 11 - Volume de controle para o tratamento final da pectina

A primeira etapa é a realização da filtração, que tem por finalidade retirar todo o líquido remanescente, além de realizar lavagens com etanol para a retirada das impurezas. A pectina proveniente dessa etapa de filtragem possui uma umidade máxima de $96,7 \%$. A corrente $F$ é determinada através da Equação 10 que permite calcular a umidade $(U \%)$, considerando um rendimento $(R \%)$, obtido em laboratório por Arrigoni et al. (2013), de 15 \% (Equação 11).

$$
\begin{aligned}
& U \%=\left(m_{G} / m_{F}\right) 100 \\
& R \%=\left(m_{G} / m_{C}\right) 100
\end{aligned}
$$

De posse desses valores, pode-se determinar a corrente $F_{1}$ por meio do balanço global para o sistema de filtração (Equação 12), e através da proporção de lavagem com etanol utilizada por Arrigoni et al. (2013), $m_{C} / V_{E 2}=0,2(\mathrm{~m} / \mathrm{V})$.

$$
V_{E}=V_{E 2}=V_{F 1}+m_{F}
$$

Baseado na recuperação do etanol realizada em laboratório no trabalho de Arrigoni et al. (2013), torna-se vantajoso adotar uma etapa adjacente ao processo de filtração em que todo o etanol gasto, retirado na corrente $F_{1}$, seja recuperado em cerca de $90 \%$. O segundo procedimento consiste na secagem da pectina. O produto úmido $(F)$ é submetido ao secador com uma umidade inicial $\left(\theta_{i}\right)$ de $96,7 \%$ e necessita de uma umidade final $\left(\theta_{f}\right)$ de no máximo $1 \%$. 
A corrente de entrada, $F$, é composta por $3,3 \%$ de pectina $\left(x_{\text {pectina }}^{F}\right.$ ) e a corrente de saída, $G$, de $99 \%\left(x_{\text {pectina }}\right)$. As vazões mássicas de ar quente, e ar seco, são determinadas aplicando o balanço material, seguindo as Equações de 1 a 4 . A Tabela 5 apresenta os resultados de cada corrente do tratamento final da pectina.

TABELA 5 - Balanço material para o tratamento final da pectina.

\begin{tabular}{cc}
\hline Variável & Valor \\
\hline$V_{E 2}$ & $201,5 \mathrm{~L} / \mathrm{h}$ \\
$m_{F}$ & $6,10 \mathrm{~kg} / \mathrm{h}$ \\
$V_{F 1}$ & $4.224,2 \mathrm{~L} / \mathrm{h}$ \\
$m_{G}$ & $6,04 \mathrm{~kg} / \mathrm{h}$ \\
$m_{G 1}$ & $194,3 \mathrm{~kg} / \mathrm{h}$ \\
$m_{F 2}$ & $188,5 \mathrm{~kg} / \mathrm{h}$ \\
$m_{H 2 O}$ & $5,8 \mathrm{~kg} / \mathrm{h}$ \\
$\Delta x$ & $0,031 \mathrm{~kg} \mathrm{H} \mathrm{O} / \mathrm{kg} \mathrm{ar}$ \\
\hline
\end{tabular}

\section{Seleção e especificações dos equipamentos}

A seleção dos equipamentos foi feita com base nas etapas laboratoriais realizadas por Arrigoni et al. (2013), e a partir dos balanços foi possível determinar a capacidade de cada equipamento. Foram propostos equipamentos que atenderiam a indústria alimentícia, como processador de frutas e estufa para secagem de frutas, além de moinhos para materiais menos impactantes. $O$ extrator foi especificado com base no processo laboratorial e por ser uma extração sob refluxo, utilizou-se um tanque de aquecimento acoplado a um condensador. O Quadro 1 mostra os equipamentos escolhidos para a área de produção e suas devidas capacidades.

TABELA 6 - Capacidade dos equipamentos do setor produtivo.

\begin{tabular}{|c|c|c|}
\hline Equipamento & Quantidade (un) & Capacidade \\
\hline Coluna de recuperação de etanol & 1 & $20000 \mathrm{~L} / \mathrm{h}$ \\
\hline Condensador & 1 & - \\
\hline Estufa industrial 1 & 2 & $15 \mathrm{t}$ \\
\hline Estufa industrial 2 & 1 & $100 \mathrm{~kg}$ \\
\hline Estufa industrial 3 & 1 & $25 \mathrm{~kg}$ \\
\hline Filtro prensa & 1 & $5000 \mathrm{~L}$ \\
\hline Filtro rotativo & 1 & $10000 \mathrm{~L}$ \\
\hline Moinho centrífugo a martelo & 1 & $90 \mathrm{a} 150 \mathrm{~kg} / \mathrm{h}$ \\
\hline Moinho de facas & 1 & $15 \mathrm{~kg}$ \\
\hline Processador de casca & 1 & $620 \mathrm{~kg} / \mathrm{h}$ \\
\hline Tanque de aquecimento & 2 & $5000 \mathrm{~L}$ \\
\hline Tanque de descanso & 1 & $10000 \mathrm{~L}$ \\
\hline Trocador de calor & 1 & $50 \mathrm{placas}$ \\
\hline
\end{tabular}

Para a determinação do grau de esterificação da pectina, deve-se ter um laboratório integrado ao setor produtivo. Com isso, foram selecionados os 
instrumentos necessários para a etapa de caracterização do produto final, que são apresentados no Quadro 2 com suas respectivas capacidades.

QUADRO 2 - Capacidade dos materiais de laboratório.

\begin{tabular}{|c|c|c|}
\hline Equipamento & Quantidade (un) & Capacidade \\
\hline Balança semi-análitica & 1 & $200 \mathrm{~g}$ \\
\hline Balão volumétrico & 1 & $100 \mathrm{~mL}$ \\
\hline Balão volumétrico & 2 & $1000 \mathrm{~mL}$ \\
\hline Béquer & 2 & $1000 \mathrm{~mL}$ \\
\hline Bureta & 2 & $50 \mathrm{~mL}$ \\
\hline Capela & 1 & - \\
\hline Dessecador & 1 & $12 \mathrm{~L}$ \\
\hline Erlenmyer & 2 & $250 \mathrm{~mL}$ \\
\hline Pipeta & 2 & $10 \mathrm{~mL}$ \\
\hline Pipeta de plástico & 500 & $2 \mathrm{~mL}$ \\
\hline Pipetador de três vias & 2 & - \\
\hline Suporte & 2 & - \\
\hline
\end{tabular}

Os reagentes necessários para as análises encontram-se na Quadro 3.

QUADRO 3 - Reagentes de laboratório.

\begin{tabular}{|c|c|}
\hline Reagente & Quantidade (un) \\
\hline Ácido Clorídrico $(\mathrm{L})$ & 1,0 \\
\hline Biftalato de Potássio $(\mathrm{kg})$ & 0,5 \\
\hline Hidróxido de Sódio $(\mathrm{kg})$ & 1,0 \\
\hline Silica Gel $(\mathrm{kg})$ & 1,0 \\
\hline
\end{tabular}

\section{CONCLUSÕES}

A partir do trabalho experimental de Arrigoni et al. (2013), foi possível propor uma unidade industrial para a obtenção de pectina, com alto grau de esterificação, extraída a partir da casca do maracujá amarelo (Passiflora Edulis Flavicarpa).

Com base na quantidade de maracujá vendida pela COOPRUJ, no ano de 2012, para as empresas de processamento de polpa de frutas no estado do Espírito Santo, foi possível estimar, através dos balanços materiais e de energia, a produção de 53 toneladas de pectina ao ano e por fim selecionar e especificar os equipamentos do processo industrial.

Além disso, o projeto mostrou-se como uma alternativa interessante para o reaproveitamento de um resíduo que atualmente recebe pouca atenção das empresas que o geram.

\section{REFERÊNCIAS}

ADETUNJI, L. R.; ADEKUNLE, A.; ORSAT, V.; RAGHAVAN, V. Advances in the pectin production process using novel extraction techniques: A review. Food Hydrocolloids, v. 62, p. 239-250, 2017. Disponível em: < https://doi.org/10.1016/j.foodhyd.2016.08.015>. doi: 10.1016/j.foodhyd.2016.08.015 
ARRIGONI, B. M.; PUGET, F. P.; DAL-BÓ, V.; SIMONELLI, G. Reaproveitamento da casca do maracujá amarelo (Passiflora Edulis Flavicarpa) para a extração química da pectina com alto grau de esterificação. Enciclopédia Biosfera: Centro Científico Conhecer. Goiânia, v. 9, n. 16; p. 2942-2951, 2013. Disponível em: < http://www.conhecer.org.br/enciclop/2013a/engenharias/Reaproveitamento\%20da\%2 0casca.pdf>.

CONAMA, Conselho Nacional do Meio Ambiente. 1986. Resolução Conama no 20, de 18 de junho de 1986. Disponível em: <http://www.mma.gov.br/port/conama/res/res86/res2086.html> Acesso em: 17 out, 2019.

COSTA, E. C. da. Secagem industrial. São Paulo: Blucher, 2007. 178 p.

FERREIRA, M. F. P; PENA, R. S. Estudo da secagem da casca do maracujá amarelo. Revista Brasileira de Produtos Agroindustriais, Campina Grande, v.12, n.1, p.15-28, 2010. Disponível <: http://www.deag.ufcg.edu.br/rbpa/rev121/Art1213.pdf >.

IBGE, Instituto Brasileiro de Geografia e Estatística. Produção Agrícola Municipal. 2018. Disponível em: <www.ibge.gov.br>. Acesso em: 11 fev, 2020.

LARA-ESPINOZA， C.; CARVAJAL-MILLÁN, E.; BALANDRÁN-QUINTANA, R.; LÓPEZ-FRANCO, Y.; RASCÓN-CHU, A. Pectin and Pectin-Based Composite Materials: Beyond Food Texture. Settings. Molecules. v.23, 2018. Disponível em: < https://doi.org/10.3390/molecules23040942>. doi: 10.3390/molecules23040942

MANEERAT, N.; TANGSUPHOOM, N.; NITITHAMYONG, A. Effect of extraction condition on properties of pectin from banana peels and its function as fat replacer in salad cream. Journal of Food Science and Technology. v.54, p. 386-397, 2017. Disponível em: <https://doi.org/10.1007/s13197-016-2475-6>. doi: 10.1007/s13197016-2475-6

OLIVEIRA, C. F. de.; GIORDANI, D. LUTCKEMIER, R.; GURAK, P. D.; CLADERAOLIVERA, F.; MARCZAK, L. D. F. Extraction of pectin from passion fruit peel assisted by ultrasound. LWT - Food Science and Technology. v. 71, p. 110-115, 2016. Disponível em: <https://doi.org/10.1016/j.Iwt.2016.03.027>. doi: 10.1016/j.Iwt.2016.03.027.

SCHULTZ, G.; LAUER, J.; LOPES, J. M.; RANGEL, R. S.; SIMONELLI, G. Modelagem e simulação dos reatores químicos BR e PFR no EMSO e GNU Octave. Enciclopédia Biosfera: Centro Científico Conhecer. Goiânia, v. 10, n. 18; p. 37363756, 2014. Disponível em: < http://www.conhecer.org.br/enciclop/2014a/ENGENHARIAS/MODELAGEM.pdf >.

SILVA, F. O. dos R.; RAMOS, J. D.; BARROCA, M. V. Subproduto de abacate na composição de substrato para mudas de maracujazeiro. Enciclopédia Biosfera: Centro Científico Conhecer. Goiânia, v. 14, n. 25; p. 1176-1184, 2017. Disponível 
em:

$<$ http://www.conhecer.org.br/enciclop/2017a/agrar/subprodutos\%20de\%20frutos.pdf >. doi: 10.18677/EnciBio_2017A96.

ZAID, R. M.; ZULARISAM, A. W.; SAKINAH, A. M. M. Effect of process parameters on pectin extraction from dragon fruit (Hylocereus polyrhizus) peels via chemical and physical treatment. Australian Journal of Basic and Applied Sciences. v. 10, p. 69-74, 2016. Disponível em:

http://www.ajbasweb.com/old/ajbas/2016/Special\%20ICCEIB/69-74.pdf>. 